\title{
Rethinking the role of affect in health communication
}

\section{Enny Das}

VU University Amsterdam
It is not difficult to find good examples of extreme scare tactics in health communication. Cigarette warning labels show images of diseased lungs and open heart surgery, anti-drinking campaigns use vivid images how drinking and driving may result in fatal car accidents, and medical professionals remind obese patients that their eating habit may end up getting them killed. Health campaigns and warnings often include highly threatening material based on the assumption that the right dose of fear may change the habits of long-term smokers, compulsive overeaters, and alcoholics. Making people feel the terrible consequences of their bad habits is thus supposed to change their minds, and get them on the right track toward a better health.

In spite of the good intentions of health education specialists, on most occasions risk groups appear completely unmoved by threatening health material and continue their bad habits in the face of imminent danger. Below I will describe the processes that drive defensive responses among risk groups and point to strategies that make them more receptive to threatening health information. Specifically, I will argue that making people feel good, rather than bad, may be more efficient in promoting health behavior change.

\section{The truth about defensive responses}

Most risk groups are well trained in warding off threatening health information. Young smokers may argue they will quit when they are older, heavy drinkers say they have no problem abstaining from alcohol for a day or two, and individuals who had unsafe sex assume their chances of getting an STD from this one time are close to zero.

Perhaps the biggest misunderstanding about such defensive responses is that they are the result of extreme fear triggered by the imagery or threatening content of a health message. In reality, excessively fearful responses to threatening health message content are just as rare as teenagers' enthusiastic responses to being picked up by one of their parents after a night out in the town with their friends. Defensive responses to threatening health information are better defined as cognitive strategies designed to protect the self-system-or 'ego' - that is linked to beliefs and strongly held values (Steele, 1988). For instance, heavy smokers may respond defensively to evidence regarding the link between smoking and lung cancer to protect the belief that they need nicotine to relieve stress, e.g., “I really need my cigarette'. Ironically, smokers may also respond defensively to threatening health evidence to protect strongly held negative, self-defeating beliefs such as: "I have too little self-constraint to quit". These beliefs may be buried deep inside the unconscious brain most of the time; much like sleeping giants blissfully unaware of personal weaknesses. When activated, however, they may prompt a vicious cycle of self-defeating thoughts and negative affect, much like the reciprocal influence of depressed moods and pessimistic thinking in depressed patients. 
A second misunderstanding is that defensive responses to threatening health messages involve mostly passive strategies such as avoiding or ignoring the evidence. Defensive responses to threatening health information often involve active, cognitive attempts to discount the personal implications of a health message, e.g., by attacking the evidence, denying its personal relevance, downplaying its seriousness, or engaging in wishful thinking. Most defensive responses to health messages thus involve biased systematic processing of the evidence with the goal to arrive at a particular, preferred conclusion, e.g., "There is no need to take this information personally" (Das, de Wit, \& Stroebe, 2003).

If defensive strategies are active cognitive attempts to defend (hidden) personal belief systems, how can health education specialists ever effectively reach target groups? Recent research suggests that the trick may be to make people feel good, rather than bad; positive moods may decrease the power of selfundermining tendencies and decrease the adoption of healthy actions.

\section{Positive moods decrease defensiveness}

In the past decade, research has confirmed that making individuals feel secure about who they are helps them confront adversity; there is now ample evidence that affirming an important aspect of the self-concept unrelated to healthe.g., 'I am a kind person'-decreases defensive processing of threatening health information (Harris \& Epton, 2009). More recently, researchers have also started examining the role of positive mood in diminishing defensive responses to threat. Several studies suggest that, much like self-affirmation, positive moods may increase risk groups' openness to threatening health information.

One study showed that a positive mood increased recall of the negative effects of caffeine intake and intentions to cut down caffeine intake among coffee drinkers (Raghunathan \& Trope, 2002). Other research among different risk groups, i.e., coffee drinkers, or smokers, demonstrated that a positive mood decreased defensive processing of threatening health messages, and increased the adoption of healthy actions. In two studies, risk groups only processed a health message with a systematic, unbiased strategy after a positive mood induction; this strategy was absent under negative mood conditions. Importantly, beneficial effects of a positive mood were observed only for high risk groups; positive mood effects reversed for not at risk groups, leading to the use of less systematic information processing strategies (Das \& Fennis, 2008; Das, Vonkeman, \& Hartmann, 2012).

Finally, there is some evidence that a positive mood also works at the unconscious level; a positive mood speeded up reaction times to smoking-related threat words, compared with neutral words, among smokers who had just read a threatening health message about the negative health consequences of smoking (Das \& Fennis, 2008). These findings suggest that a positive mood attunes the unconscious mind to threatening information that is relevant to the self; a capacity that may increase effective selfregulation.

In sum, happy moods promote implicit attention to and unbiased processing of threatening health information under highly particular conditions, i.e., only when the information is personally relevant. A positive mood may thus increase individuals' flexibility in responding to incoming information, and help them decide when paying close attention may further personal goal attainment; a very helpful tool indeed in modern information-cluttered society. The finding that positive moods may 
increase systematic information processing of aversive information stands in apparent contrast to previous findings regarding the relationship between positive moods and information processing. In the next section, I will discuss this relationship in more detail, and examine potential origins of mood-induced responses to self-threatening information.

\section{Feeling good improves self-regulation}

In- and outside the academic world happy moods have long been associated with shallow thinking; only negative moods were supposed to promote serious and contemplative thought. However, more recent studies suggest a different side to happy moods, positive affect, and positive emotions. Whereas it is true that negative moods are generally associated with systematic, narrow, focused, and analytic forms of processing (see Schwarz \& Clore 1996 for a review), positive moods and positive emotions promote not only shallow, heuristic information processing, but also prompt a more flexible, intuitive, and broader state of mind (Fredrickson, 2001; Isen 1999). For instance, Alice Isen, pioneer in this particular research area, and her colleagues found that positive affect increased creative problem solving, the generation of unusual associations, and more efficient decision-making. More recent studies found that positive mood also increases cognitive flexibility and access to implicit, intuitive knowledge (Bolte, Goschke, \& Kuhl, 2003).

Research also suggests a positive relationship between positive affect, intuitive knowledge, and self-regulation (Baumann \& Kuhl, 2002). Positive affect and emotions increase coping resources that help individuals effectively deal with difficult situations. In addition, positive emotions predict resilience to adversity and the use of broad-minded coping strategies. Finally, positive emotions have also been related to physiological recovery processes; compared with neutral conditions, positive emotion conditions enhanced cardiovascular recovery (see Fredrickson, 2001).

Feeling good may thus help individuals put things into a bigger perspective and deal efficiently with adversity. These findings may help explain why positive mood decreases defensive processing of self-threatening information. Consider again the example of the heavy smoker who strongly believes he has too little self-constraint to quit smoking and who starts a vicious cycle of ruminative, limited thought patterns and negative emotions whenever reminded of his bad habit. A positive mood may provide a way out of a vicious cycle by liberating him from the tight grip of selfdefeating thoughts, and by increasing access to alternative-more flexible, creative-ways of thinking, and better ways of coping. In this new outlook on life, improving the situation at hand and taking the necessary steps toward a healthier life becomes a real possibility. Health messages that address this possibility may then find fertile ground.

\section{Concluding comments}

In this article I chose to focus on converging evidence and commonalities between different lines of research related to positive mood, information processing, and health, because I believe that a focus on the big picture may help further research in this area. Nevertheless, important differences exist between conceptualizations and consequences of e.g. mood, affect and discrete emotions; and these differences are worth mentioning and examining further. Barbara Fredrickson and her colleagues conducted groundbreaking work in examining effects of discrete positive and negative emotions and found, for example, that joy and contentment increased a broadened mindset, and that fear and anger narrowed this mindset, 
compared with neutral conditions (Fredrickson \& Branigan, 2005).

The commonalities and differences between self-affirmation and mood also need further investigation. Self-affirmation is different from positive mood in at least two ways: it involves some important aspect of the self, whereas the self is not necessarily implicated in mood, and it is unrelated to explicit measures of mood (e.g., Steele, 1988). Nevertheless, there is considerable overlap on the conceptual level. For instance, asking individuals to recall three happy experiences may improve mood but also affirm the self-concept at the unconscious level. Affirming an important self-related value may not affect explicit mood but, like mood, restore an individual's inner balance. It is plausible that self-affirmation and mood affect different processes at the explicit level but both increase access to implicit, intuitive self-relevant knowledge.

Communicating with risk groups involves conveying bad news most of the time, and health education specialists vary in strategy to achieve this goal: whereas some will try to shock risk groups into understanding the consequences of unhealthy lifestyles, others may try subtle strategies in order to prevent upsetting message receivers. Based on the available evidence, health education specialists do not have to cover up the facts, as long as they make sure risk groups are in the right mood to accept bad news without getting lost in it. Health education efforts that make sure message receivers feel comfortable before they process threatening health information stand a better chance of truly reaching a target audience.

\section{References}

Baumann, N., \& Kuhl, J. (2002). Intuition, affect, and personality: Unconscious coherence judgments and selfregulation of negative affect. Journal of Personality and
Social Psychology, 83, 1213-1223. doi: 10.1037/00223514.83.5.1213

Bolte, A., Goschke, T., \& Kuhl, J. (2003). Emotion and intuition: Effects of positive and negative mood on implicit judgments of semantic coherence. Psychological Science, 14, 416-421. doi: 10.1111/1467-9280.01456

Das, E., \& Fennis, B. M. (2008). In the mood to face the facts: When a positive mood increases systematic processing of self-threatening messages. Motivation and Emotion, 32, 221-230. doi: 10.1007/s11031-008-9093-1

Das, E., de Wit, J.B.F, \& Stroebe, W. (2003). Fear appeals motivate acceptance of recommendations: Evidence for a positive bias in the processing of persuasive messages. Personality and Social Psychology Bulletin, 29, 650-664. doi: 10.1177/0146167203029005009

Das, E., Vonkeman, C., \& Hartmann, T. (2012). Mood as a resource in dealing with health recommendations: How mood affects information processing and acceptance of quit-smoking messages. Psychology and Health, 27, 116127. doi: $10.1080 / 08870446.2011 .569888$

Fredrickson, B. L. (2001). The role of positive emotions in positive psychology: The broaden-and-build theory of positive emotions. The American Psychologist, 56, 218-226. doi: 10.1037/0003-066X.56.3.218

Fredrickson, B. L., \& Branigan, C. (2005). Positive emotions broaden the scope of attention and thought-action repertoires. Cognition and Emotion, 19, 313-332. doi: 10.1080/02699930441000238

Harris, P. R, \& Epton, T. (2009). The impact of selfaffirmation on health cognition, health behavior and other health-related responses: A narrative review. Social and Personality Psychology Compass, 3, 962-978. doi: 10.1111/j.1751-9004.2009.00233.x

Isen, A. M. (1999). Positive affect. In T. Dalgleish \& M. J. Power (Eds.), Handbook of cognition and emotion (pp. 521-539). New York: Wiley \& Sons. Isen, A. M. (2004). Some perspectives on positive feelings and emotions: Positive affect facilitates thinking and problem solving. In A. S. R. Manstead, N. Frijda, \& A. Fischer (Eds.), Feelings and emotions: The Amsterdam symposium (pp. 263-282). Cambridge, NY: Cambridge University Press.

Raghunathan, R., \& Trope, Y. (2002). Walking the tightrope between feeling good and being accurate: Mood as a resource in processing persuasive messages. Journal of 
Personality and Social Psychology, 83, 510-525. doi: 10.1037/0022-3514.83.3.510

Schwarz, N., \& Clore, G. L. (1996). Feelings and phenomenal experiences. In E. T. Higgins \& A. Kruglanski (Eds.), Social psychology: A handbook of basic principles (pp. 433-465). New York: Guilford Press.

Steele, C. M. (1988). The psychology of self-affirmation: Sustaining the integrity of the self. In L. Berkowitz (Ed.), Advances in experimental social psychology (Vol. 21, pp. 261-302). New York: Academic Press.

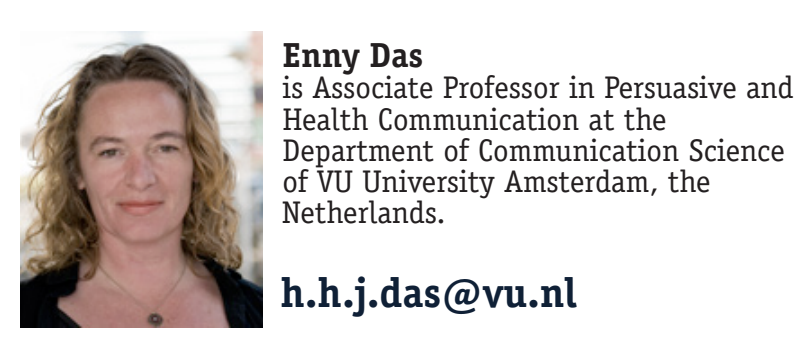

Enny Das

Department of Communication Science of VU University Amsterdam, the

h.h.j.das@vu.nl 